\title{
Effects of a Storytelling Program with Drama Techniques to Understand and Accept Intellectual Disability in Students 6 - 7 Years Old. A Pilot Study
}

\author{
Paraskevi Giagazoglou, Maria Papadaniil \\ Department of Physical Education and Sport Sciences, Aristotle University of Thessaloniki, Serres, Greece \\ Email:pgiagaz@phed-sr.auth.gr
}

How to cite this paper: Giagazoglou, P., \& Papadaniil, M. (2018). Effects of a Storytelling Program with Drama Techniques to Understand and Accept Intellectual Disability in Students $6-7$ Years Old. A Pilot Study. Advances in Physical Education, 8, 224-237.

https://doi.org/10.4236/ape.2018.82020

Received: April 6, 2018

Accepted: May 22, 2018

Published: May 25, 2018

Copyright $\odot 2018$ by authors and Scientific Research Publishing Inc. This work is licensed under the Creative Commons Attribution International License (CC BY 4.0).

http://creativecommons.org/licenses/by/4.0/

\begin{abstract}
A very crucial issue in special education, as well as in education in general, is the integration itself in the educational system. Although integration oriented schools offer a wide range of opportunities for social integration, incidents of social rejection cannot always be eradicated. Given that, the knowledge and understanding of disability creates a tendency for positive attitudes toward it, the evaluation and timely implementation of specially designed awareness interventions is mandatory and it should take place to help children with and without disabilities coexist harmonically in and out of school. This study aims at determining the effect of a 12 teaching hours intervention program on the potential change in attitudes toward disability of students in the first grade of primary school. The intervention program consisted of reading and theatrical play of a story tale referring to a small turtle born with Down syndrome. The results showed a significant positive effect on the understanding and the acceptance of intellectual disability.
\end{abstract}

\section{Keywords}

Intervention, Inclusive Education, Theatrical Play, Physical Education, Dramatic Environment

\section{Introduction}

A very important issue that concerns special education as well as education in general is that of inclusive education. It is generally considered to be a multifaceted concept which includes acceptance and assessment of diversity and diversification, taking into account human rights, social justice, equality issues, as well 
as the social model of disability and the socio-political model of education. Also, the concept of inclusive education includes the process of school transformation and focuses on the right of children to access education (Lindsay, 2007).

Although the inclusive education model is designed to support children with disabilities, there are also many benefits for children with typical development. It facilitates the coexistence with peers with disabilities, the development of empathy and the understanding of each other's needs, the acceptance of diversity and the offer of assistance, the improvement of self-image and the reduction of behavioural problems as well as the development of friendly relations with children with disabilities (Turnbull, 1995).

However, despite the fact that schools which are integration oriented offer significant opportunities for social inclusion, they are often likely to leave room for social rejection. The coexistence of children with and without special educational needs or disabilities cannot ensure a direct understanding and acceptance of disability. Therefore, it is imperative to understand disability and create a positive attitude so as to ensure their harmonious coexistence. Research shows that children with disabilities are not always accepted by children with a typical development and that their attitude is often negative (Siperstein, Parker, Bardon, \& Widaman, 2007). This may be due to many factors such as the lack of knowledge of children in relation to disability, the difficulty of teachers to facilitate coexistence between children with and without disabilities, negative attitudes that can be formed by parents or society as well as to the feeling discomfort towards diversity. Therefore, it is important to understand both the attitude of children towards disability as well as the way that this attitude can change (Tregaskis, 2000). Since knowledge and understanding of disability is positively related to positive attitudes, the implementation and evaluation of appropriately designed awareness programs is imperative and should be done in a timely manner so as to promote the harmonious coexistence of children with and without disabilities. Thus, even if children do not have a positive attitude towards children with disabilities and feel "uncomfortable", there is a belief that these behaviours can change at an early age through direct and structured contact with children with disabilities and through indirect experiences through books, videos, or discussions (Favazza \& Odom, 1997).

Studies indicate that the implementation of programs to raise awareness at school is necessary in setting positive attitudes (Morin, Rivard, Crocker, Boursier, \& Caron, 2013). Negative attitudes towards disabled students develop due to ignorance (Ison, McIntyre, Rothery et al., 2010). However, when students are trained on the issue of diversity or disability, they are more likely to develop more positive attitudes in this direction. Given that negative attitudes towards people with disabilities are believed to be formed in the early stages of the development process (Krahe \& Altwasser, 2006), it is important that the education of students takes place during the first school years so as to transfer their positive attitude throughout their school life, but also outside the school. 
It was found that interventions contained guided discussion and storytelling concerning disability and social behaviour issues, have had positive effects on attitudes (De Boer, Pijl, Minnaert, \& Post, 2014). Boutot (2007) claimed that guided discussions can begin with the use of books narrating stories with characters depicted as "no typical". More specifically, the use of books is described as a means of solving social and/or emotional problems in the practice of bibliotherapy where issues of everyday life can be resolved through the indirect experiences of the characters of the book (Carlson, 2001). Well written picture books can help younger children develop multiple perspectives and thus increase their understanding of others (Morgan, 2009). Through picture books reading and discussions, teachers can promote disability awareness in their classrooms (Ostrosky, Mouzourou, Dorsey, Favazza, \& Leboeuf, 2015). Shuman (2006) suggested that storytelling opens up the possibility of empathy.

Similar to storytelling, drama is highly recommended as an intervention instrument because it can also stimulate students' emotions and promote their empathy (Edmiston, 2000). By participating in a drama activity, students are being occupied in the characters' world. The use of drama techniques can change students' views of others by role-playing and by accepting others' perspectives. Read (2008) suggested that storytelling and drama share many common features. Both build on children's capacity for play, deal with significant issues, involve multiple intelligences, appeal to different learning styles, suspend norms and identity temporarily but also set rules and directions for a particular context. If these two methods were used together, they would have full potential in interventions by appealing students' interest, attention and imagination. To act upon the stories being told, children can be supported by being invited to engage actively and emotionally in the story world, not only with the characters but as the characters. Empathy and acceptance are cultivated when students try to understand themselves and others in role-playing.

Despite the potential of storytelling and drama in moral education, there are only a limited number of empirical studies that examined their effectiveness on peer acceptance of students with disabilities (Lindsay \& Edwards, 2013; Law et al., 2017). However, in order to be effective, the intervention should be be planned, intensive, purposeful, and sustained over a period of time, since the occasional reading of a book does not seem to be enough to modify attitudes and behaviours (Trepanier-Street \& Romatowski, 1996). Thus, it was suggested that interventions aimed at promoting attitudes towards peers with disability should include stories, class activities, practical exercises, and discussions, several sessions over a longer period of time rather than a brief one-off session, and an experimental design (Lindsay \& Edwards, 2013). For that reason, a detailed analysis of a fairytale where the central hero is a turtle with Down syndrome has been analysed in this study. Although there have been several studies of storytelling about various forms of disability, intellectual disability has not yet been studied through storytelling and theatrical play. 
The purpose of the current study was to to evaluate the effectiveness of a storytelling program with drama techniques on first grade students' awareness and acceptance of children with intellectual disabilities. It is expected that the intervention program will help students to understand and accept intellectual disability through storytelling and theatrical play activities based on the content of the book. The program was applied to a first grade class which included a girl with Down syndrome, in order to get the girl's classmates involved in a dramatic environment in a storybook referring to a small turtle born with Down syndrome.

\section{Methodology}

\subsection{Participants}

The study involved 34 students (19 boys and 15 girls) aged $6-7$ years (mean age $80.66 \pm 9.4$ ). The students attended two different groups of the first grade in a primary school of a north town of Greece. The school was selected by convenience sampling, since there was an inclusive class in the first grade which was attended by a girl with Down syndrome. In addition, both the classroom teacher and the school principal were willing to participate in the research. The group which included the girl with intellectual disability was the intervention group, while the other was the control group. The intervention group consisted of 14 children ( 7 boys and 7 girls) of which 12 were of normal development, one with Down's syndrome and one with Attention-Deficit Hyperactivity Disorder (ADHD), while the control group was composed of 20 children (12 boys and 8 girls) with typical development. All participants apart from the students with Down syndrome and ADHD participated in the questionnaire completion tests in the form of an interview for assessing perceptions (attitudes, behaviour) on disability one week before and after the intervention.

The intervention group attended a 12 hours storytelling program with drama techniques, while children of the control group followed the regular school schedule. All parents or legal guardians provided written informed consent prior participation, which was approved by an Institutional Review Board for use of Human subjects, allowing the children's involvement in the program and access to relevant information. This study was approved by the ministry of education Athens, Greece and by the Research Ethics Board, Aristotle University of physical education, Serres, Greece.

\subsection{Testing Procedures and Instrumentation}

\subsubsection{Measurement Process}

The process of assessing the behaviour of children took place one week before the beginning and one week after the end of the intervention. The questionnaires were completed by two specially trained researchers with training in the application of psychometric tests. Each researcher undertook the assessment of a student who was interviewed individually in a quiet space of his/her own school, without distractions. The researcher, who made the assessment, read out the 
questions to each of the students separately and completed the answers given by them. The first item completed was from the Understanding Disability Scale where each child was asked to draw a person with a disability. If the child did not know what a disability was, the researcher did not give any clarification and encouraged him/her to try to guess and draw a person with a disability as he/she can imagine. When coding this item, the content of each drawing was recorded as "irrelevant" when the drawing did not represent a person with a disability. The responses to the open question "What do you know about a disabled person?" were filled in the same way.

The items of the two Scales were used, Acceptance Scale for Kindergartner-Revised and the Behavioral Intentions Scale, translated in Greek language. First, the two scales were translated from English to Greek by two expert researchers from our department. Then, back translations were also done in order to examine if the items of Greek forms is consisted with the original form, or not and final Greek forms of the two scales were composed. Before the data collection process, a pilot study was performed to 10 children in order to understand if the items are comprehensible for Greek language. The two scales have been previously validated and used in different countries (Boer et al., 2014; Ersan et al., 2017; Nikolaraizi et al., 2005).

The application process lasted about 15 minutes for each child.

\subsection{Understanding Disability Scale}

The Understanding Disability Scale (UDS) was used to determine the impact of the intervention on information on disability. UDS is a quality tool, which consists of two parts and evaluates the understanding of disability. In the 1st part the student is asked to draw "a person with disability or a person with special needs", while in part 2 he is asked to answer the open question "What do you know about a person with a disability?". The Understanding Disability Scale is an adaptation of the Revised Version of the Primary Student Survey of Handicapped Persons (Esposito \& Peach, 1983). The adaptation included removing the scales that evaluate factors other than understanding disability (Van Hooser, 2009). The scale has been weighted and has been rated as suitable for preschoolers up to 7 years of age (Esposito \& Peach, 1983).

\subsection{Acceptance Scale for Kindergartners-Revised (ASK-R)}

The ASK-R questionnaire of Favazza \& Odom (1999) was used to determine the impact of intervention on the levels of acceptance of children with typical development towards children with disabilities. This questionnaire was created using the Acceptance Scale tool (Voeltz, 1980) for assessing attitudes of first-grade school children towards disability, and it was later revised (ASK-R). The Acceptance Scale tool is a psychometrically valid tool with a split-half reliability factor (corrected according to Spearman Brown) equal to 0.82 and a Cronbach internal reliability factor of 0.77 used for older school children (Voeltz, 1980). The ASK-R is a modified version of the Acceptance Scale tool de- 
signed for a wider age range and includes questions that can be understood by children at a lower development level. According to Favazza \& Odom (1996), these scales were selected because they are quite simple for a 4-year-old child and still refer to a 10-year-old.

The ASK-R (ASK-R; Favazza \& Odom, 1999) is an 18-item tool designed to measure the emotional and behavioural factor of the attitudes of preschool children with typical development towards children with disabilities. It has three point scale (Yes $=2$ point, Maybe $=1$ point or no $=0$ point). The score reflects the acceptance level of children with disabilities or children who are different. The score can get 0 - 36 points with the highest scores reflecting higher acceptance. Rates from 0 to 11 indicate low acceptance, from 12 to 24 moderate and from 25 to 36 high acceptance (Favazza \& Odom, 1997; Favazza, Phillipsen, \& Kumar, 2000; Nikolaraizi et al., 2005; Sulla, 2011). The scale has a high reliability index (Cronbach's alpha $=0.87$, Split Half $=0.91$ ). Note that for the purposes of this study in order to assess the attitudes of children towards solely intellectual disability, the word disability was replaced with the word mental disability. For example the word disability in the item "Would you play with a kid if he had a disability" was replaced with intellectual disability.

\subsection{Behavioral Intentions Scale (BIS)}

The BIS is designed to determine willingness to interact with a child with a disability. This scale is based on the Behavioral Intentions Scale (Roberts \& Lindsell, 1997) and the Friendship Activity Scale (Siperstein, 1980). Developmentally inappropriate items were eliminated to create a list of 15 activities typical for young children. The participant was presented with a picture of a child with Down Syndrome and read a short description about it. The interviewer then asks, "Would you do... with this child?" inserting an activity typical of young child's day. These activities fall into 5 categories: helping behaviors (e.g. Help him/her put on his/her winter coat for recess?), sharing behaviors (e.g. Lend him/her your crayons?), physical proximity (e.g. Stand next to him/her while waiting in line?), common activities (Play with him/her during recess?), and familiarity (e.g. Tell him/her about your family?). The child responds by saying "yes," "no," or "maybe". This scale is scored by assigning point values of 0 (no), 1 (maybe), or 2 (yes). Higher scores indicate more positive behavioral intentions toward the target children.

\subsection{Storytelling Program with Drama Techniques}

A storytelling with drama techniques intervention program was applied in first grade inclusive class during physical education lessons. It was suggested that if these two tools were combined, they would have ample potential in interventions by engaging students' interest, attention and imagination. The book was chosen called "A star for Joy" (Giagazoglou-Papouda, 2016) and aimed to get the girl's classmates involved in a dramatic environment in a storybook referring to a little turtle born with Down syndrome. Firstly, at the beginning of each lesson 
hour, students were sat on a carpet in a semi-circle row. Then the researcher started to narrate the story. The narrator interrupted the story at some points where there was dramatic tension and intense emotional alternations. A discussion was made, beyond the theatrical role, about the different characters, the disability of little turtle and the consequences in her life. A critical point for a successful intervention is the all the participants to deeply comprehend all the basic characters of the story. It was given a full description about feelings and behaviors of all the protagonists. How the little turtle Joy and her family feel and how encounter their fears, rumors or rejection. Later on, the story gives emphasis to the fact that someone with Down syndrome, just like everyone, have certain strengths and weaknesses. However, this someone would also like to make friends and be loved. In general, during the intervention hours, the researcher taught a different part of the story according to a detailed lesson plan that employed many techniques in drama education. These techniques included "theatrical play", "teacher in role", "hot-seating", "frozen-image", "thought-tracking", "conscience alley" and "mantle of the expert" (Neelands \& Goode, 2000). All those different drama techniques serve as narrative actions to motivate students to think and talk and promote their empathy (Edmiston, 2000). By participating in a drama activity, students are being immersed in the characters' world. The use of drama can change students' views of others by role-playing and by adopting others' perspectives.

\section{Results}

\subsection{Understanding Disability Scale}

The first research question, "What do first grade children understand about the nature of intellectual disability?" was explored using the UDS by evaluating the drawing and the question "What do you know about intellectual disability?" It was found from the results that none of the non-inclusive class and only 3 participants from the inclusive class gave a correct answer. The majority of children for both groups gave "don't know" responses when asked to define intellectual disability. Examples from their answers were a person with an intellectual disability is someone who: has nothing to eat and hungry, is homeless, has cough, is very sick. It was concluded, that regardless of direct classroom exposure to disability (a classmate with Down Syndrome in the intervention group), the majority of participants did not understand the term intellectual disability.

However, it seemed that there was a major improvement of awareness about intellectual disability for the intervention group, as assessed by the percentages of drawings but also by the question about disability. In contrast, in the control group there was no change in percentages for both factors (Table 1).

\subsection{Acceptance Scale for Kindergartners-Revised (ASK-R)}

An analysis of variance (one-way ANOVA) with repeated measures was used to examine the effects of Time (PRE-POST) and Group (EG-CG) for the variables of ASK-R. Table 2 shows the scores of acceptance scale between the two groups 
Table 1. Percentage of disability understanding.

\begin{tabular}{|c|c|c|c|}
\hline & & Pre intervention & Post intervention \\
\hline \multirow{6}{*}{ Intervention } & \multicolumn{3}{|c|}{ Drawing } \\
\hline & Irrelevant & $9(75 \%)$ & $1(8,3 \%)$ \\
\hline & ID & $3(25 \%)$ & $11(91.7 \%)$ \\
\hline & \multicolumn{3}{|c|}{ What do you know about disability? } \\
\hline & Irrelevant & $10(83.3 \%)$ & $1(8.3 \%)$ \\
\hline & ID & $2(16.7 \%)$ & $11(91.7 \%)$ \\
\hline \multirow{6}{*}{ Control } & \multicolumn{3}{|c|}{ Drawing } \\
\hline & Irrelevant & $20(100 \%)$ & $20(100 \%)$ \\
\hline & ID & $0(0 \%)$ & $0(0 \%)$ \\
\hline & \multicolumn{3}{|c|}{ What do you know about disability? } \\
\hline & Irrelevant & $20(100 \%)$ & $20(100 \%)$ \\
\hline & ID & $0(0 \%)$ & $0(0 \%)$ \\
\hline
\end{tabular}

Table 2. Scores of ASK-R between the two groups, pre and post intervention.

\begin{tabular}{cccccc}
\hline & $\begin{array}{c}\text { Pre } \\
\text { intervention }\end{array}$ & $\begin{array}{c}\text { Post } \\
\text { Intervention }\end{array}$ & Variation & $\%$ & $\mathrm{P}$ \\
\hline Intervention & $19.7 \pm 8.1$ & $26.4 \pm 8.6$ & +6.7 & $+34.05 \%$ & 0.004 \\
Control & $19.8 \pm 7.6$ & $21.4 \pm 5.8$ & +1.6 & $+8.1 \%$ & 0.410 \\
\hline
\end{tabular}

pre and post intervention. It was found that the acceptance of children in relation to children with intellectual disabilities increased $34.05 \%$ in the intervention group, an increase found to be statistically significant $\left(\mathrm{F}=4.77, \mathrm{p}=0.004, \eta_{p}^{2}=\right.$ $0.18)$.

\subsection{Behavioral Intentions Scale (BIS)}

The BIS was used to investigate children's reported interactions with children with a disability. An analysis of variance (one-way ANOVA) with repeated measures was used to examine the effects of Time (PRE-POST) and Group (EG-CG) for the variables of Perceived Attributes Scale (PAS). The ANOVA tests revealed a significant Group $\times$ Time interaction on BIS scores $(F=7.22, p=$ $\left.0.001, \eta_{p}^{2}=0.243\right)$. The intervention group showed a significant increase in BIS scores (5.2 \pm 4.7 vs $9.7 \pm 7$ in pre- vs. post-training, $\mathrm{p}<0.05)$ following intervention. However, no differences were observed within the control group in BIS scores $(4.6 \pm 3.7$ vs $5.2 \pm 3.5$ pre- vs. post-training, $\mathrm{p}>0.05)$. Table 3 shows the scores of Behavioral Intentions Scale between the two groups pre and post intervention.

\section{Discussion}

In the current study, storytelling and drama techniques were combined to enhance students' awareness and acceptance of children with ID. It was found 
Table 3. Scores of BIS between the two groups, pre and post intervention.

\begin{tabular}{cccccc}
\hline & $\begin{array}{c}\text { Pre } \\
\text { Intervention }\end{array}$ & $\begin{array}{c}\text { Post } \\
\text { Intervention }\end{array}$ & Variation & $\%$ & $\mathrm{P}$ \\
\hline Intervention & $5.2 \pm 4.7$ & $9.7 \pm 7.0$ & +4.5 & $+86.7 \%$ & $<0.05$ \\
Control & $4.6 \pm 3.7$ & $5.2 \pm 3.5$ & +0.6 & $+13.1 \%$ & $>0.05$ \\
\hline
\end{tabular}

from the present results that storybook intervention changed positively children's acceptance and awareness of peers with disability. These findings support the view that books can be a powerful tool for increasing awareness, knowledge, understanding and acceptance of oneself and others, including those with differences and disabilities (Gilmore \& Howard, 2016). Moreover, recent studies suggested that while children are guided to engage in the story world, they may experience changes in attitudes (Adomat, 2012; Law et al., 2017; Wright, Diener, \& Kemp, 2013).

Following the suggestion of Boutot (2007) who claimed that guided discussions can begin with the use of books describing stories with characters depicted as "non-typical", a book story with a turtle born with a Down syndrome was selected. This book sends the message to children that if someone born with Down, syndrome may take longer to learn but still like to participate in play activities, has the same feelings with others and delight in childhood experiences. Such educational practices can help the initiation of discussions about the characteristics of disabilities. Additionally, as it has been mentioned in the past, as the occasional reading of a book does not seem to be enough to form attitudes and behaviours (Trepanier-Street \& Romatowski, 1996), the program had a duration of 12 teaching hours and combined with drama techniques.

Using drama techniques simultaneously with reading, the researcher interacted with students by asking questions during the storytelling session. More specifically, students were invited to role-play the characters, to help them solve problems and to explore the characters' feelings and motivations of certain behaviours. For example, when studying the part of the story when other little animals exclude the turtle from their play because she was slow and being an object of ridicule by others, students needed to think and talk in turtle's role. By doing so, students would be able to understand more about little turtle's feelings. The above drama techniques are useful teaching tools to promote proper education. Students are being encouraged to discuss and to express their opinions both in-role or being themselves in the drama context. Thus, during the drama activities, they feel more comfortable since there are no right or wrong answers.

As it concerns the results of students of the intervention group before the program, had low levels of knowledge on intellectual disability. This was reflected by the assessment through the Understanding Disability Scale. In particular, when students were asked to draw a child with an Intellectual Disability (ID), 9 children (75\%) drew something unrelated (e.g. a child who has broken his leg or a child with a dog) while only 3 children (25\%) drew a child with an ID. However, no one of the control group drew a child with an ID. Some chil- 
dren from both groups, when asked to draw a child with an ID, drew a child on a wheelchair. However, when it was clarified that they were asked to draw a child with ID rather than physical disability, they erased their drawing and designed something irrelevant.

This choice is probably due to the fact that in Greece, the concept of "disability", for the majority of young children and adults, is identified with a person with apparent physical disability. Even in the case of the intervention team, where there was the girl with Down's syndrome who had obvious appearance characteristics due to her disability, was not understood that it was the case of a child with disability. This is consistent with a study by Hodkinson (2007) according to which, when primary school students were asked to draw a child with disability, the majority of the participants drew children in wheelchairs, suggesting that children view disability as a physical condition. Also, in a study by Hong et al. (2014), preschool children seemed to understand that understanding disability is limited to features related to special equipment. The prevalence of motor disability over others is probably due to the fact that it is easier for children to understand the concept of disability when it is linked to an external feature such as a wheelchair. Therefore, the different characteristics in the appearance of a young child with Down syndrome are not enough for younger children in order to understand ID.

However, after the storytelling program, the awareness of disability increased significantly for the intervention group, while there was no change in the control group. Therefore, it appears that the intervention program has had a significant impact on the understanding of ID, as can be verified by the children's drawings. In addition, previous research has shown that the implementation of different intervention programs has contributed significantly to the understanding of disability. For example, in a study, the presentation of an educational video with a view to improve the knowledge level of children aged $7-12$ years old, in relation to a specific syndrome, had positive results (Holtz \& Tessman, 2007). Similarly, an intervention program that included activities in order to inform about various issues related to disabilities, the difficulties that a person with disabilities may be facing and the elimination of stereotypes in children aged $6-12$ years, had positive results (Triliva, Anagnostopoulou, Hatzinikolaou, Chimienti, \& Mastorakou, 2009). Finally, an intervention program included information activities such as discussions with a disabled person, using sign language, Braille, information on the Paralympic Games, had a positive effect on the levels of understanding disability, on children aged 9 - 11 (Ison et al., 2010).

Similar to the results obtained from the evaluation of the drawing, there were the results from the children's answers to the question "What do you know about disability?". Their responses reflected low levels of knowledge about ID for both groups. In fact, none of the control group and only 2 students from the intervention group, knew something about intellectual disability. However, after the implementation of the intervention, there was a statistically significant change in knowledge about ID for the experimental group. This is in line with 
Sulla's (2011) study results where pre-school children after a whole year of integration could distinguish different types of disability and realised how a disability can affect a child's life.

Regarding the participants' acceptance levels towards children with intellectual disabilities, the initial measurements showed moderate levels of acceptance for both groups. After the storybook program, there was a statistically significant improvement in the levels of disability acceptance for the intervention group, while there was no significant improvement for the control group. However, it was suggested that attitudes of children towards their classmates with disability are strongly influenced by the levels of knowledge about disability (Ison et al., 2010). Unwanted behaviours and social exclusion are often the result of the lack of relevant knowledge of children. As disability perceptions often shape attitudes and behaviours (Nowicki, 2006; Hunt \& Hunt, 2004), it appears that after the intervention program of this study, both the level of knowledge of children and the acceptance of ID have improved. For that matter, it has been reported in the past that a key mechanism for improving attitude is sensitization interventions (Shannon et al., 2009).

It appears from the results of this study, that the students of the intervention group received detailed and substantial information through storytelling and drama techniques. Through the detailed analysis of storytelling, they have gained substantial knowledge of the ID and the effects in the life of the person himself and those around him. The intervention program combined two key factors that influence children's attitudes towards disability: the provision knowledge through storytelling and extensive discussions and the contact with disability in the framework of structured psychomotor activities using drama techniques. So far, to the best of our knowledge, there has been no study in which this type of intervention was applied to an intervention group of first grade children. Studies using either storytelling (Trepanier-Street \& Romatowski, 1996; Cameron \& Rutland, 2006) or coming in contact with people with disabilities (Sulla, 2011) with a view to influence the behaviour of pre-school and first grade students, mostly yielded positive results. It can be said that the variables that we focused on in the intervention are indeed sensitive to educational actions and can be increased in developmental age. However, it has been shown that interventions combining the two above-mentioned factors have better results than their individual application (Favazza \& Odom, 2000; Law et al., 2017). Finally, giving information about the difficulties of peers with ID and the ways in which the latter can participate in and contribute to school activities, can serve greater understanding of the conditions of these children.

\section{Conclusion}

In conclusion, it appeared that the use of a selected children's book on intellectual disability together with drama techniques, could be an effective strategy to promote positive attitudes towards disability. The form of the current intervention seems to help children to be able to see things through the perspective of 
their peers with intellectual disabilities. Knowing that children's negative attitudes are formed early in the developmental process (Krahe \& Altwasser, 2006), and that the level of understanding of the nature of disability is positively correlated with positive attitudes (Hodkinson, 2007), the implementation of properly designed program can provide a more supportive class environment. In this environment, students encourage one another in positive interactions and show greater tendency to positively interact with a classmate with ID (Ostrosky et al., 2015). The findings of the present study reveal a promising first step. We encourage other researchers to join our effort to develop effective intervention programs for inclusive education.

\section{References}

Adomat, D. S. (2012). Drama's Potential for Deepening Young Children's Understandings of Stories. Early Childhood Education Journal, 40, 343-350. https://doi.org/10.1007/s10643-012-0519-8

Boutot, E. A. (2007). Fitting in: Tips for Promoting Acceptance and Friendships for Students with Autism Spectrum Disorders in Inclusive Classrooms. Intervention in School and Clinic, 42, 156-161. https://doi.org/10.1177/10534512070420030401

Cameron, L., \& Rutland, A. (2006). Extended Contact through Story Reading in School: Reducing Children's Prejudice toward the Disabled. Journal of Social Issues, 62, 469-488. https://doi.org/10.1111/j.1540-4560.2006.00469.x

Carlson, R. (2001). Therapeutic Use of Story in Therapy with Children. Guidance \& Counseling, 16, 92-99.

De Boer, A., Pijl, S. J., Minnaert, A., \& PostW. (2014). Evaluating the Effectiveness of an Intervention Program to Influence Attitudes of Students towards Peers with Disabilities. Journal of Autism and Developmental Disorders, 44, 572-583.

https://doi.org/10.1007/s10803-013-1908-6

Edmiston, B. (2000). Drama as Ethical Education. Research in Drama Education: The Journal of Applied Theatre and Performance, 5, 63-84. https://doi.org/10.1080/135697800114203

Ersan, D. T., Ata, S., \& Kaya, S. (2017). Examining the Psychometric Properties of Acceptance Scale for Kindergarten-Revised (ASK-R) in Turkish. Journal of Education and Training Studies, 5, 58-63. https://doi.org/10.11114/jets.v5i5.2129

Esposito, B., \& Peach, W. (1983). Changing Attitudes of Preschool Children toward Handicapped Persons. Exceptional Children, 49, 361-363.

https://doi.org/10.1177/001440298304900411

Favazza, P. C., \& Odom, S. L. (1996). Use of the Acceptance Scale to Measure Attitudes of Kindergarten-Age Children. Journal of Early Intervention, 20, 232-248. https://doi.org/10.1177/105381519602000307

Favazza, P. C., \& Odom, S. L. (1997). Promoting Positive Attitudes of Kindergarten-Age Children toward People with Disabilities. Exceptional Children, 63, 405-418. https://doi.org/10.1177/001440299706300308

Favazza, P. C., \& Odom, S. L. (1999). Acceptance Scale for Kindergarten-Revised $(A S K-R)$. Roots \& Wings.

Favazza, P. C., Phillipsen, L., \& Kumar, P. (2000). Measuring and Promoting Acceptance of Young Children with Disabilities. Exceptional Children, 66, 491-508. https://doi.org/10.1177/001440290006600404 
Giagazoglou-Papouda, P. (2016). A Star for Joy. Ellinoekdotiki Publications. http://www.ellinoekdotiki.gr/displayITM2.asp?ITMID=1571\&LANG=GR

Gilmore, L., \& Howard, G. (2016). Children's Books That Promote Understanding of Difference, Diversity and Disability. Journal of Psychologists and Counsellors in Schools, 26, 218-251. https://doi.org/10.1017/jgc.2016.26

Hodkinson, A. (2007). Inclusive Education and the Cultural Representation of Disability and Disabled People: Recipe for Disaster or Catalyst of Change? An Examination of Non-Disabled Primary School Children's Attitudes to Children with Disabilities. Research in Education, 77, 56-76. https://doi.org/10.7227/RIE.77.5

Holtz, K. D., \& Tessman, G. K. (2007). Evaluation of a Peer-Focused Intervention to Increase Knowledge and Foster Positive Attitudes toward Children with Tourette Syndrome. Journal of Developmental and Physical Disabilities, 19, 531-542.

https://doi.org/10.1007/s10882-007-9042-z

Hong, S. Y., Kwon, K. A., \& Jeon, H. J. (2014). Children's Attitudes towards Peers with Disabilities: Associations with Personal and Parental Factors. Infant and Child Development, 23, 170-193. https://doi.org/10.1002/icd.1826

Hunt, C. S., \& Hunt, B. (2004). Changing Attitudes toward People with Disabilities: Experimenting with an Educational Intervention. Journal of Managerial Issues, 266-280.

Ison, N., McIntyre, S., Rothery, S., Smithers-Sheedy, H., Goldsmith, S., Parsonage, S., \& Foy, L. (2010). "Just Like You": A Disability Awareness Programme For Children That Enhanced Knowledge, Attitudes and Acceptance: Pilot Study Findings. Developmental Neurorehabilitation, 13, 360-368. https://doi.org/10.3109/17518423.2010.496764

Krahe, B., \& Altwasser, C. (2006). Changing Negative Attitudes towards Persons with Physical Disabilities: An Experimental Intervention. Journal of Community \& Applied Social Psychology, 16, 59-69. https://doi.org/10.1002/casp.849

Law, Y. K., Lam, S. F., Law, W., \& Tam, Z. W. (2017). Enhancing Peer Acceptance of Children with Learning Difficulties: Classroom Goal Orientation and Effects of a Storytelling Programme with Drama Techniques. Educational Psychology, 37, 537-549. https://doi.org/10.1080/01443410.2016.1214685

Lindsay, G. (2007). Educational Psychology and the Effectiveness of Inclusive Education/Mainstreaming. British Journal of Educational Psychology, 77, 1-24. https://doi.org/10.1348/000709906X156881

Lindsay, S., \& Edwards, A. (2013). A Systematic Review of Disability Awareness Interventions for Children and Youth. Disability and Rehabilitation, 35, 623-646. https://doi.org/10.3109/09638288.2012.702850

Morgan, H. (2009). Picture Book Biographies for Young Children: A Way to Teach Multiple Perspectives. Early Childhood Education Journal, 37, 219. https://doi.org/10.1007/s10643-009-0339-7

Morin, D., Rivard, M., Crocker, A. G., Boursier, C. P., \& Caron, J. (2013). Public Attitudes towards Intellectual Disability: A Multidimensional Perspective. Journal of Intellectual Disability, 57, 279-292. https://doi.org/10.1111/jir.12008

Neelands, J., \& Goode, T. (2000). Structuring Drama Work: A Handbook of Available Forms in Theatre and Drama (2nd ed.). Cambridge: Cambridge University Press.

Nikolaraizi, M., Kumar, P., Favazza, P., Sideridis, G., Koulousiou, D., \& Riall, A. (2005). A Cross-Cultural Examination of Typically Developing Children's Attitudes toward Individuals with Special Needs. International Journal of Disability, Development and Education, 52, 101-119. https://doi.org/10.1080/10349120500086348

Nowicki, E. A. (2006). A Cross-Sectional Multivariate Analysis of Children's Attitudes 
towards Disabilities. Journal of Intellectual Disability Research, 50, 335-348. https://doi.org/10.1111/j.1365-2788.2005.00781.x

Ostrosky, M. M., Mouzourou, C., Dorsey, E. A., Favazza, P. C., \& Leboeuf, L. M. (2015). Pick a Book, Any Book: Using Children's Books to Support Positive Attitudes toward Peers with Disabilities. Young Exceptional Children, 18, 30-43. https://doi.org/10.1177/1096250613512666

Read, C. (2008). Scaffolding Children's Learning through Story and Drama. IATEFL Young Learners, 2, 6-9.

Roberts, C., \& Lindsell, J. (1997). Children's Attitudes and Behavioral Intentions toward Peers with Disabilities. International Journal of Disability, Development, and Education, 44, 133-145. https://doi.org/10.1080/0156655970440205

Shannon, C. D., Tansey, T. N., \& Schoen, B. (2009). The Effect of Contact, Context, and Social Power on Undergraduate Attitudes toward Persons with Disabilities. Journal of rehabilitation, $75,11$.

Shuman, A. (2006). Entitlement and Empathy in Personal Narrative. Narrative Inquiry, 16, 148-155. https://doi.org/10.1075/ni.16.1.19shu

Siperstein, G. N. (1980). Adjective Checklist (ACL) and Friendship Activity Scale (FAS): Instruments for Measuring Children's Attitudes. Boston: Center for Social Development and Education, University of Massachusetts.

Siperstein, G. N., Parker, R. C., Bardon, J. N., \& Widaman, K. F. (2007). A National Study of Youth Attitudes toward the Inclusion of Students with Intellectual Disabilities. $E_{X}$ ceptional Children, 73, 435-455. https://doi.org/10.1177/001440290707300403

Sulla, E. (2011). Examining Children's Attitudes towards Disability after One Year in a Reverse Integrated Setting. Doctoral Dissertation, Montréal: Concordia University.

Tregaskis, C. (2000). Interviewing Non-Disabled People about Their Disability-Related Attitudes: Seeking Methodologies. Disability and Society, 15, 343-355. https://doi.org/10.1080/09687590025711

Trepanier-Street, M. L., \& Romatowski, J. A. (1996). Young Children's Attitudes toward the Disabled: A Classroom Intervention Using Children's Literature. Early Childhood Education Journal, 24, 45-49. https://doi.org/10.1007/BF02430551

Triliva, S., Anagnostopoulou, T., Hatzinikolaou, S., Chimienti, G., \& Mastorakou, A. (2009). The Development and Evaluation of a Program to Sensitize Greek Grammar School Students to Issues Relating to Disability. The European Journal of Counselling Psychology, 1, 3-17. https://doi.org/10.5964/ejcop.v1i1/2.8

Turnbull, A. P. (1995). Exceptional Lives: Special Education in Today's Schools. Old Tappan, NJ: Merrill/Prentice Hall.

Van Hooser, K. N. (2009). An Investigation of Preschool-Aged Children's Perceptions of Their Peers with a Disability. Unpublished Doctoral Dissertation, Ames, IA: Iowa State University.

Voeltz, L. M. (1980). Children's Attitudes toward Handicapped Peers. American Journal of Mental Deficiency, 84, 455-464.

Wright, C., Diener, M. L., \& Kemp, J. L. (2013). Storytelling Dramas as a Community Building Activity in an Early Childhood Classroom. Early Childhood Education Journal, 41, 197-210. https://doi.org/10.1007/s10643-012-0544-7 